\title{
MANAGEMENT OF INTRACRANIAL ATHEROSCLEROTIC DISEASE
}

\author{
Bilgehan Atılgan ACAR*, Atilla Özcan ÖZDEMIR** \\ *Sakarya University Faculty of Medicine, Department of Neurology, Sakarya, TURKEY \\ **Eskişehir Osmangazi University Faculty of Medicine, Department of Neurology, Eskişehir, TURKEY
}

\begin{abstract}
Intracranial Atherosclerotic Disease (ICAD) is a significant cause of ischemic stroke which is used to be neglected. Due to developments in imaging technologies as well as increased use of endovascular interventional procedures and conventional catheter angiography on practice of stroke, ICAD found being much more associated with the etiology of ischemic stroke and transient ischemic attack today. That it is more common among Asians, Hispanics and Afro-Americans compared to caucasians indicates the heterogeneous tendency of this subgroup of stroke in terms of race and ethnicity. Stroke due to ICAD occurs in various mechanisms such as thrombotic occlusion, artery to artery embolism, hemodynamic ischemia and penetrating vascular occlusion, and moreover, clinically significant findings can be seen in the presence of moderate stenosis $(<\% 50)$. It is required to be clarified whether such various mechanisms have a role in frequent occurrence of recurrent strokes in ICAD, and which strategies are required to be applied in diagnosis and treatment. In this review, the management of ICAD will be discussed in accompaniment of current publications.
\end{abstract}

Key Words: Atherosclerosis, stroke, intracranial, intracranial atherosclerotic disease.

\section{INNTRAKRANIAL ATEROSKLEROTIK HASTALIĞA YAKLAȘIM}

\section{ÖZET}

İntrakranial aterosklerotik hastalık (İKAH), iskemik inmenin genellikle göz ardı edilen önemli bir nedenidir. Son yıllarda görüntüleme tekniklerindeki gelişmeler ve de konvansiyonel kateter anjiografi ile endovasküler girişimsel işlemlerin inme pratiğinde kullanımının artması sayesinde, günümüzde iskemik inme ve geçici iskemik atak etyolojisi ile çok daha fazla ilişkilendirilmeye başlanmıştır. Asyalı'larda, İspanik ve Afrika kökenli Amerikalı'larda, beyaz ırka oranla daha sık görülmesi, inmenin bu alt grubunun ırk-etnisite açısından heterojen eğilimini göstermektedir. İKAH'da inme, trombotik oklüzyon, arterden artere emboli, hemodinamik iskemi ve penetran damar oklüzyonu șeklinde farklı mekanizmalar altında gelişebilir ve üstelik ılımlı stenoz (<\%50) varlığında dahi klinik olarak anlamlı bulgular görülebilmektedir. Rekürren inmelerin İKAH'da sık görülmesinde bu farklı mekanizmaların rolü olup olmadığı, tanı ve tedavide hangi stratejilerin uygulanması gerektiği cevap bekleyen sorulardandır. Bu derlemede İKAH'a yaklaşım güncel yayınlar eșliğinde tartışılacaktır.

Anahtar Sözcükler: Ateroskleroz, inme, intrakranial, intrakranial aterosklerotik hastalık.

\section{INTRODUCTION}

Stroke is a significant cause of death and disability throughout the world. Approximately 80 $90 \%$ of all strokes are of ischemic origin [1,2]. Randomized controlled trials were conducted concerning many symptomatic or asymptomatic (stroke-free) patients with extracranial carotid stenosis or atrial fibrillation and long-term follow- up data were obtained, whereas, ICAD was not assessed in most of these clinical trials and in stroke guidelines or was collected under extracranial carotid stenosis $[3,4]$. However, ICAD differs from extracranial atherosclerotic stroke with aspects such as risk factors and stroke patterns (5).

\footnotetext{
Corresponding author: Bilgehan Atılgan Acar, MD. Sakarya University Faculty of Medicine, Department of Neurology, Sakarya, TURKEY. Telephone: $+904445400 \quad$ E-mail: bilgehanacar@hotmail.com

This article should be cited as following: Acar B.A, Özdemir A.Ö. Management of intracranial atherosclerotic disease. Turkish Journal of Cerebrovascular Diseases 2019; 25 (1): 1-10. doi:10.5505/tbdhd.2019.47855
} 


\section{PATHOPHYSIOLOGY \& RISK FACTORS}

Atherosclerosis is a pathological condition characterized by increased cholesterol, lipid accumulation and increased connective tissue in the vessel wall of the coronary, cerebral and peripheral arteries. Hypertension, diabetes mellitus, dyslipidemia and smoking are common vascular risk factors for both intracranial and extracranial atherosclerosis, however dyslipidemia is more closely associated with extracranial atherosclerosis, whereas hypertension, diabetes mellitus and metabolic syndrome are with intracranial atherosclerosis [6]. In addition, several factors such as endothelial dysfunction, inflammatory and immunological agents, plaque rupture, and other factors play a role in the pathophysiology of intracranial atherosclerosis [7].

Besides, the lipoprotein biomarkers (such as high apolipoprotein B/AI, low serum adiponectin, increased lipoprotein-a) can be used to determine the severity of ICAD [8]. Intracranial atherosclerosis can result in ischemic stroke or transient ischemic attack (TIA) with different mechanisms. While, of those, the "artery to artery thromboembolism" and "small vessel occlusion with the spread of atheroma into small penetrating vessel orifice" are more frequent two mechanisms, the "development of hemodynamic insufficiency with progression of intra-luminal stenosis" and "thrombotic occlusion" are relatively rare [5, 7].

\section{EPIDEMIOLOGY}

ICAD is held responsible for $10 \%$ of ischemic strokes in U.S.A, whereas for up to $50 \%$ of ischemic strokes in Asia [2]. The actual prevalence of ICAD may be higher, due to the inadequacy of the present diagnostic methods to detect symptomatic but non-stenotic atherosclerotic plaques. The incidence of intracranial plaque and stenosis in autopsy spicimens of fatal strokes was $62.2 \%$ and $43.2 \%$ in patients with ischemic stroke, respectively; and $48.8 \%$ and $17.5 \%$, in patients with hemorrhagic stroke, respectively [3]. 5.8\% of intravenous stenosis (> 30\%) found in brain infarcted autopsies $(>30 \%)$ was associated with stroke (due to the presence of superimposed or ulcerated plaques with thrombosis), and about one third of them had a degree of stenosis between $30 \%$ and $75 \%$ [3]. In the same study, the history of myocardial infarction was found associated with intracranial plaque, and the history of previous stroke was found associated with intracranial stenosis in multiple variation analyses; and the male sex and the presence of diabetes mellitus were reported to be significantly associated with both intracranial plaque and intracranial stenosis. It was reported that the risk factors vary depending on the localization of the stenosis; the basillary artery stenosis is associated with advanced age and hyperlipidemia, and the middle cerebral artery stenosis is associated with female sex and black race, and the intracranial carotid artery stenosis is associated with diabetes mellitus [7].

The prevalence of ICAD is higher in the Asian, Hispanic and Afro-Americans compared to the white race, and such race-ethnic variations could be in relation with risk factor profiles, lifestyle patterns and the change in the genetic tendency [2]. For example, while hypertension, diabetes mellitus and hyperlipidemia burden in AfroAmericans explain this situation, on the other hand, it is reported that genetic and environmental factors may play an important role in the pathogenesis of ICAD in Asian population [8].

\section{DIAGNOSIS}

Computed tomographic angiography (CT-A), magnetic resonance angiography (MR-A) and transcranial doppler (TCD) inspections are preferred more as they are considered as noninvasive, easy-to-access and safe methods compared to conventional catheter angiography, which is considered as a golden standard. The SONIA (Stroke Outcome and Neuroimaging of Intracranial Atherosclerosis) study showed that the negative predictive values of TCD and MR-A were high ( $85 \%$ and $87 \%$ respectively) in ICAD diagnosis, while positive predictive values thereof were restricted (50\% and $66 \%$ respectively) [9]. Although it is a reference standard method, the conventional catheter angiography is not routinely used because it is an invasive method, however CT-A having a specificity and sensitivity more than 95\% is preferred for the diagnosis [2]. Such noninvasive diagnostic imaging methods have difficulties to distinguish "is the lesion in a nature of atherosclerotic plaque", or "is it in compliance with other patterns such as partial occlusive thrombus, vasospasm, vasculitis or preocclusive 
Moyamoya disease?". Conventional catheter angiography is not deemed required in general as it will not significantly change the clinical management in most of the cases suspected particularly for first attack symptomatic ICAD picture; because the biggest disadvantage is the stroke risk, which can be seen at a rate of 1.2\% [7, 10]. However, in rare cases where alternative etiologies such as Moyamoya disease, intracranial dissection and vasculitis are suspected, the catheter angiography should be performed certainly in order to accurately measure the degree of stenosis of the affected artery, to distinguish between advanced stenosis / occlusion, to detect collateral flow patterns, and to evaluate other intra- and extracranial arteries [7].

"Intravascular ultrasound" (IVUS), which is performed with an ultraminiaturized transducer mounted at the tip of catheter during angiography, was included in the cardiovascular medicine literature as an important method of imaging coronary vessel wall in interventional cardiology [11]. The IVUS technique may provide a virtual histological image in large intracranial vessels; in an in vitro study conducted on intracranial arterial segments with atherosclerotic plaque, the virtual histological images obtained by IVUS and 7 Tesla magnetic resonance imaging (7T MRI) showed good correlation with histopathological analysis [12].

High resolution magnetic resonance vessel wall imaging (hMR-VWI) technique shows the morphology of atherosclerotic plaque, artery wall and surrounding structures beyond simple lumen changes [13]. In addition to intracranial atherosclerotic plaques, it can also show nonatherosclerotic pathological changes in the affected segment. hMR-VWI is generally used as 3 Tesla in order to see in sufficient resolution of the structures inside the vessel wall, however, in more recent studies, $7 \mathrm{~T}$ ultra-hMR-VWI technique can detect vessel wall pathologies that are not visible in conventional imaging (which are confirmed histopathologically) [14].

\section{DIFFERENTIAL DIAGNOSIS}

Arterial dissection, fibromuscular dysplasia, cerebral vasoconstriction, primary and secondary vasculitis, Moyamoya disease and other vasculopathies that cause intracranial artery stenosis should come to mind in differential diagnosis of ICAD. While these are seen much rarer than ICAD in adult population, some clinical and radiological features can be beneficial in the differential diagnosis. When distinguishing this sub-group which is non-atherosclerotic among intracranial large vessel diseases from atherosclerotic ones, radiological methods such as hMR-VWI technique or genetic methods such as "genome-wide association studies (GWASs)" (where all genomes are analyzed to define the genetic variations) are used [13]. Nonatherosclerotic intracranial major vessel diseases such as intracranial arterial dissections, Moyamoya disease (characterized by progressive stenosis caused by fibrocellular intimal thickening), vascular inflammatory diseases, vasospasm and immunological diseases are more commonly encountered in adolescents and youngadult age periods [13].

\section{TREATMENT}

The rate of stroke recurrence in ICAD was reported very high with a rate of 4\%-19\% per year [15]. Antithrombotic agents constitute basis of treatment in symptomatic ICAD patients. Angioplasty and stenting or bypass surgery are rarely performed. Another significant factor is to fight against risk factors.

\section{Antithrombotic Treatment Anticoagulant therapy}

The "Warfarin Aspirin Symptomatic Intracranial Disease" (WASID) study compared the medical treatment options in the patients with symptomatic ICAD (with minor stroke or transient ischemic attack (TIA)) of which 50\%-99\% stenosis was proven angiographically; no difference was found in a 1.8-year follow-up between warfarin (target INR between 2-3) and aspirin (1300 $\mathrm{mg}$ /day) groups in the term of recurrent stroke and death caused by vascular reasons; however aspirin was found safer than warfarin in terms of major hemorrhage and non vascular mortality rate [16]. There is no systematic study investigating the effect of non-vitamin $\mathrm{K}$ oral anticoagulants on stroke prevention in ICAD [7].

\section{Antiplatelet therapy}

Antiplatelet agents used in ischemic stroke are aspirin, clopidodrel and aspirin-slow release dipyridamole combination, and these drugs, which are known to be effective in all subgroups of non- 
cardioembolic ischemic stroke, have no randomized controlled trials compared to placebo or each other in the symptomatic ICAD subgroup, which is particularly at high risk of recurrence.

The studies "Cloidogrel With Aspirin in Acute Minor Stroke or Transient Ischemic Attack" (CHANCE) and "Platelet-oriented inhibition in new TIA and minor ischemic stroke" (POINT) evaluated the protective efficiency of "aspirin+clopidogrel" therapy on first 90-day ischemic vascular cases compared to "aspirin only" therapy in the patients with minor stroke or TIA, and more aggressive antithrombotic therapy (aspirin + clopidogrel) was reported to be more effective in acute period $[17,18]$. In a post-hoc analysis of CHANCE study including the patients having intracranial MR-A inspections, cases with intracranial atherosclerosis were shown to have a higher recurrent stroke rate than those without intracranial atherosclerosis, and it was reported that there was no significant difference in the response to dual antiplatelet therapy between between patients with and without intracranial atherosclerosis (interference $\mathrm{p}=0.2)[19]$.

In the "Clopidogrel plus aspirin versus aspirin alone for reducing embolisation in patients with acute symptomatic cerebral or carotid artery stenosis" (CLAIR) study, the "aspirin + clopidogrel" combination therapy was shown to be more effective than "aspirin only" therapy in terms of the decrease of microembolic signals particularly in the patients with symptomatic intracranial atherosclerosis [20].

An important feature of clopidogrel is that this agent is an inactive prodrug and must be converted to its active metabolite with CYP2C19. Clopidogrel resistance is thought to be much more common in Asians than in Caucasians [15].

Ticagrelor is a drug that is frequently used in patients with coronary atherosclerotic disease, that has the same mechanism of action as clopidogrel (platelet ADP receptor P2Y12 inhibition), that however lacks of resistance similar to the one in clopidogrel as it is an active agent. In a subgroup analysis of the study named "Acute Stroke or Transient Ischaemic Attack Treated with Aspirin or Ticagrelor and Patient Outcomes" (SOCRATES) where it is compared with aspirin to prevent recurrent stroke in patients with acute cerebral ischemia of atherosclerotic origin, the Ticagrelor was reported to be superior to aspirin to prevent myocardial infarction or death in 90 days in the patients with acute ischemic stroke or TIA associated with ipsilateral atherosclerotic stenosis [21]. However, these findings should be interpreted carefully since the SOCRATES study was not limited to patients with ICAD.

Cilostazol is a phosphodiesterase III inhibitor antiplatelet, besides having vasodilator, antiinflammatory, anti-atherogenic agent efficacy [15]. In a multicenter, double-blind, placebo-controlled clinical trial, the combination of "aspirin + cilostazol" was shown to be superior in the prevention of progression of stenosis in patients with symptomatic ICAD when compared with "aspirin only" [22]. In another study where the "aspirin + cilostazol" combination was compared with the "aspirin + clopidogrel" combination, no significant difference was found between the groups in preventing the progression of intracranial atherosclerosis and the formation of new ischemic lesions [23].

The number of studies on the use of prasugrel, varopaxar (selective protease activator receptor-1 antagonist), etc., as well as other new antiplatelet agents is inadequate [7].

\section{Statin Therapy}

In a post-hoc analysis of the study named "The Stroke Prevention by Aggressive Reduction of Cholesterol Levels" (SPARCL), atorvastatin was shown to be effective compared with placebo in reducing the risk of recurrent stroke in patients with major vascular disease [24], however, strong comments were not made since the SPARCL study was not intended to examine this specific relationship, and further studies to support these data are required.

\section{Modification of Risk Factors}

Combating hypertension, hyperlipidemia, diabetes mellitus and smoking are important components in the treatment of all vascular diseases including intracranial atherosclerosis.

In a post-hoc analysis of WASID study, when the patients with ICAD those whose blood pressure could not be controlled enough or who had high cholesterol levels in the follow-up are compared with the patients who were well controlled in terms of such risk factors, the rate of mortality from stroke, myocardial infarction and vascular causes was found significantly higher [25].

Lifestyle changes, including diet, weight loss, physical activity, are other important factors that 
reduce the risk of stroke in ICAD. The study named "The Stenting and Aggressive Medical Management for Preventing Recurrent Stroke in Intracranial Stenosis" (SAMMPRIS) is the first stroke prevention study including tightsupervision of multiple risk factors through protocols, and it was recommended in a preliminary analysis investigating the relationship between risk factor control and patient outcomes in the follow-up of patients in the medical arm of the study, that blood pressure, cholesterol and physical inactivity should be treated aggressively to prevent future vascular events in patients with ICAD. Physical activity was the strongest predictor of good outcome in the medical arm of the SAMMPRIS study [26].

The aggressive medical treatment protocol applied in (SAMMPRIS) study can be summarized as follows: aspirin $325 \mathrm{mg}$ + clopidogrel $75 \mathrm{mg}$ (with $600 \mathrm{mg}$ loading dose) for 3 months and aspirin alone beyond 90 days; to keep blood pressure below 140/90 $\mathrm{mmHg}$ for nondiabetic patients and below 130/90 $\mathrm{mmHg}$ for diabetic patients with angiotensin-converting enzyme (ACE) inhibitor + diuretic therapy; to keep LDLcholesterol level $\leq 70 \mathrm{mg} / \mathrm{dL}$, HDL-cholesterol level $\geq 40 \mathrm{mg} / \mathrm{dL}$, triglyceride level $\leq 150 \mathrm{mg} / \mathrm{dL}$ with statin therapy; to quit smoking; fasting blood glucose $<126 \mathrm{mg} / \mathrm{dL}$ ve $\mathrm{HbA} 1 \mathrm{c}<6.5 \mathrm{mg} / \mathrm{dL}$ and regular diet and exercise [27].

\section{Surgical Therapy}

In an extensive, multi-centere, randomized study conducted on patients with symptomatic extracranial carotid occlusion, distal carotid occlusion or middle cerebral artery stenosis; the surgical application was inefficient to protect patients against stroke in the group that underwent extracranial-intracranial anastomosis surgery compared with the group that used 1300 $\mathrm{mg} /$ day aspirin; and the incidence of stroke was significantly higher in the group that underwent surgical therapy, compared with the patients with moderate cerebral artery stenosis $\geq 70 \%[28,29]$. Therefore, intracranial bypass surgery is an option in patients with ICAD, but is not recommended.

\section{Interventional Therapies}

In symptomatic intracranial stenosis, the risk of recurrent stroke in patients receiving medical treatment was reported to be $11 \%$ per year and $14 \%$ in two years [30,31]. The rate of annual stroke recurrence is $19 \%$ in patients with stenosis level between $70 \%$ and $99 \%$. All these high recurrence risks led clinicians to seek endovascular treatment strategies out of medical treatments or in addition to medical treatments in ICAD.

Although endovascular treatment including angioplasty and stenting in intracranial major vascular disease seems promising in nonrandomized studies [33], the results from SAMMPRIS study showed that the aggressive medical treatment is superior to advanced intracranial atherosclerosis which recently became symptomatic $[34,35]$ (Figure I-V).

In the guideline published by the American Heart Association / American Stroke Association, stenting with the Wingspan system used in the SAMMPRIS study is not recommended in severe intracranial stenosis-induced stroke or TIA [36].

\section{Angioplasty}

Although angioplasty is a feasible technique for intracranial major vascular disease, the data in the literature are limited to single-center, retrospective observational reports including a few cases, and periprocedural stroke or mortality rates vary between $4-50 \%$. Intracranial angioplasty has some disadvantages such as sudden elastic withdrawal of the artery, dissection, acute vessel closure, postprocedural residual stenosis $>50 \%$, and restenosis.

\section{Submaximal angioplasty}

In two studies with a small number of patient series (74 and 41), the balloon angioplasty was performed with slow expansion below normal value to limit periplastic procedural complications and approximately $5 \%$ periprocedural procedural complications developed in both studies $[37,38]$. Technical success was reported as $92 \%$ in one of the studies, and recurrent stroke within 1 year was reported as $3 \%$ in the other study. Submaximal angioplasty made with balloon as 50$70 \%$ of nominal vessel diameter may be a promising strategy for a safe revascularization in patients with ICAD in the future [7].

\section{Stenting}

In the "Stenting of Symptomatic Atherosclerotic Lessions in the Vertebral or Intracranial Arteries" (SSYLVIA) study, which is a non-randomized, non-prospective study, 61 patients whose stenosis level was $\geq 50 \%$ were 

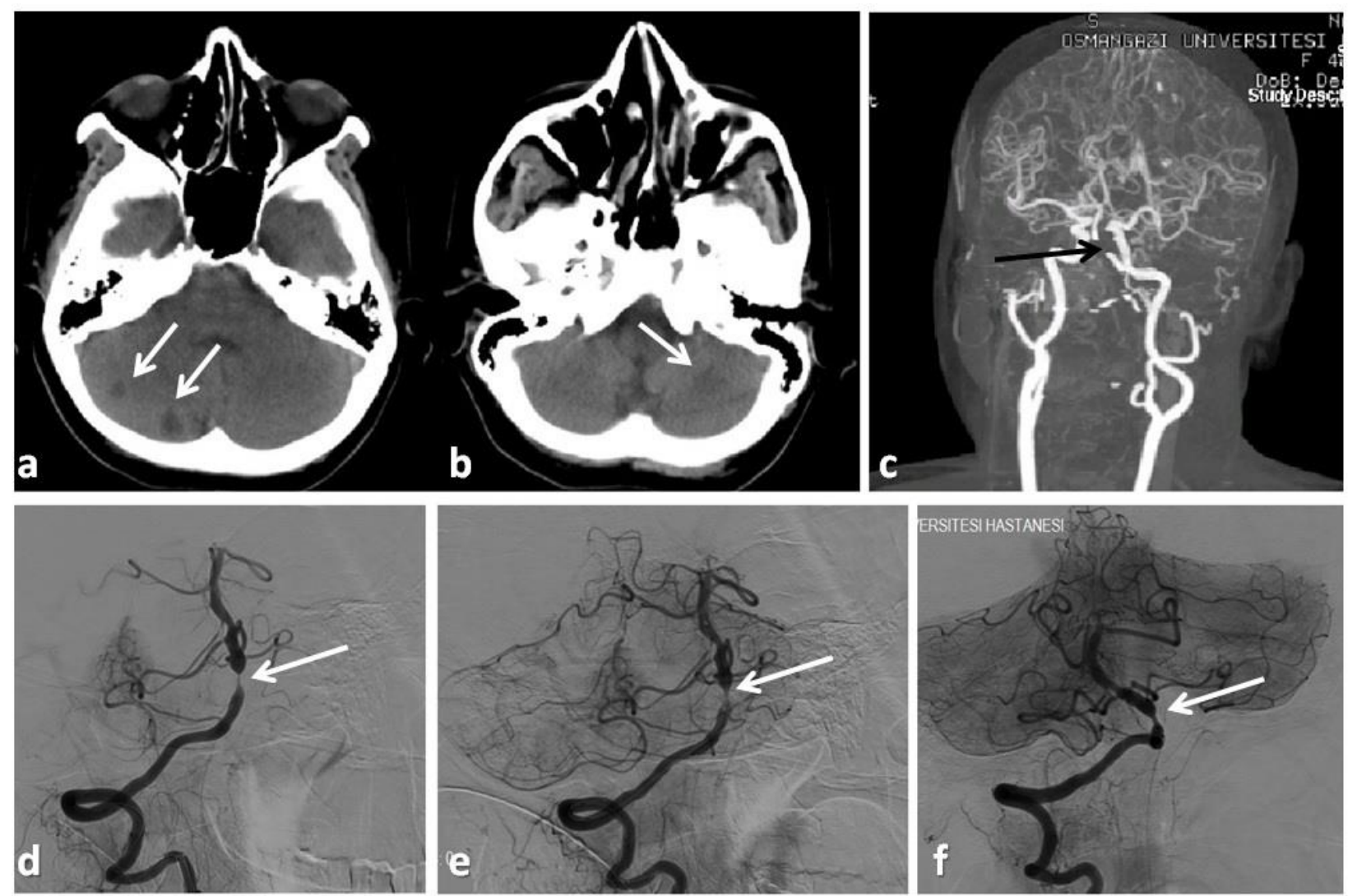

Figure I. (Patient-1) 48 years old female patient. Complaints: loss of balance, dizziness, nausea-vomiting, ringing in both ears. The neurological examination revealed hypotonia at the right upper and lower extremities, mild dysmetry at the right side and right truncal ataxia. Medical History: hypertension, vertigo / posterior circulation transient ischemic attacks. Medicines used; valsartan hydrochlorothiazide 160 / $12.5 \mathrm{mg}$; amlodipine $10 \mathrm{mg}$; aspirin $100 \mathrm{mg}$, clopidogrel $75 \mathrm{mg}$. a) Hypodense lesions consistent with right cerebellar infarction on axial non-contrast computed tomography (CT) b) Hypodense lesion consistent with left cerebellar infarction in axial non-contrast CT c) A lesion which could not be distinguished between advanced stenosis or occlusion in basillary artery in CTangiography (maximum intensity projection - reconstruction coronal planes) imaging d) Image of advanced (99\%) stenosis in the basilar artery before anterior inferior cerebellar artery (AICA) in angiogram e) Decrease in stenosis and partial improvement in posterior circulation in angiogram after angioplasty with Gateway $1.5 \times 15 \mathrm{~mm}$ balloon" f) Significant reduction in stenosis and significant improvement in posterior circulation in angiogram after stenting with "Enterprise 4x20 mm stent" (not performed due to the risk of postdilatation rupture).

placed with stent (43 of them had intracranial stenosis and the stenting was successful in 37 thereof); and 12 out of 37 patients who were placed with stent $(32.4 \%)$ developed re-stenosis (level $>50 \%$ ) within 6 months [39].

The Wingspan stent was specifically produced for intracranial atherosclerotic lesions, and 451 patients having symptomatic ICAD (with stenosis level 70-90\%) were randomized in SAMMPRIS study to "only aggressive medical treatment group" and to "Wingspan stent + aggressive medical treatment group". The study, which was planned to be completed in 2013, was ended in 2011. 30-day stroke or death was 14.7\% in the group placed with stent and $5.8 \%$ in the group that received aggressive medical treatment $(\mathrm{p}=0.002)$.

VISSIT study is another randomized controlled study intended to compare "PHAROS Vitesse neurovascular balloon-expandable stent system + medical treatment" with "medical treatment only" in the patients with symptomatic intracranial stenosis (stenosis severity $\geq 70 \%$ ) in terms of safety, benefit and efficacy [40]. Because of the negative data obtained in another similar study, this study was stopped by the sponsor and therefore an early analysis of the results was made [40]. The "stroke, death or intracranial 
hemorrhage" was found significantly higher in the stent group at the end of 30th day compared with the medical group ( $24 \%$ and $9 \%$, respectively). In the same vascular region, "stroke or TIA" was significantly higher in the stent group at 12 months than in the medical group (36\% and 15\%, respectively).

Although it is reported that reported that stenting to prevent stroke in patients with ICAD is harmful in these two randomized study, some specialists deem stenting as a last resort in some patients with intracranial stenosis with a high degree of stenosis that does not respond to medical treatment.

\section{CONCLUSION}

Different mechanisms can play a role in the pathophysiology of stroke in ICAD, and the risk of recurrence is very high in this stroke type. Failures in treatment are perhaps due to failure to understand this disease which has a heterogeneous character. To identify the underlying pathophysiological cause and to choose the right treatment strategy can turn the situation in our favor. The discovery of advanced diagnostic methods, the new alternatives to medical and genetic therapies, the developments in endovascular techniques will strengthen our hand.
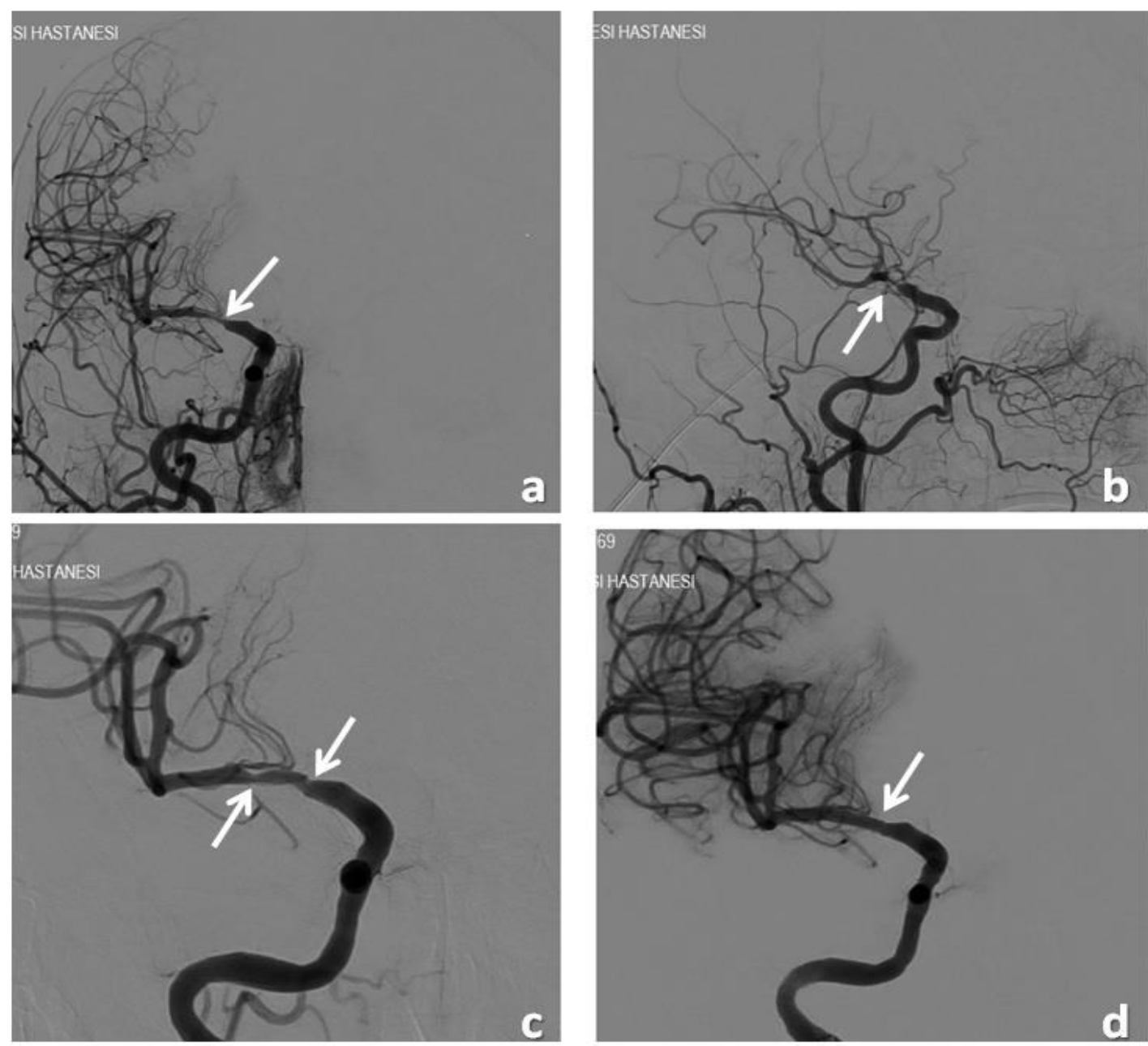

Figure II. (Patient-2) 50 years old female patient. Complaints: transient strength loss attack in the left arm and leg (TIA). The patient has a medical history of left hemispheric stroke and hyperlipidemia, the medicines used are: aspirin $100 \mathrm{mg}$, clopidogrel $75 \mathrm{mg}$, atorvastatin $20 \mathrm{mg}$. a) Image consistent with long segment (> 70\%) stenosis in right middle cerebral artery $\mathrm{M} 1$ in the angiogram (AP=Anterior-Posterior image) b) Right oblique image of stenosis in angiogram c) Image in angiogram consistent with dissection developed after submaximal angioplasty with " $3 \times 15$ mm coronary balloon" d) Improvement in stenosis and dissection and increased distal blood flow with "Neuroform stent". 

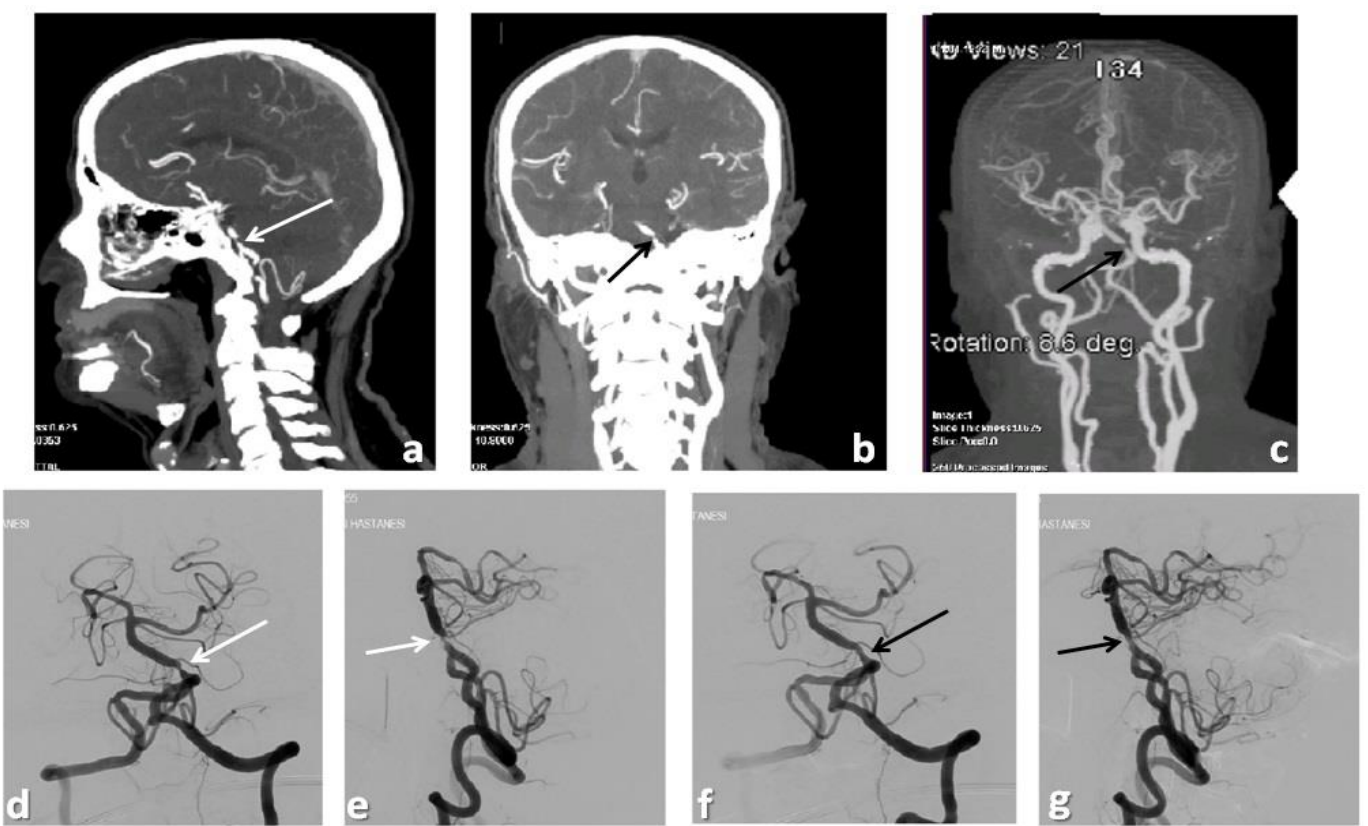

Figure III. (Patient-3) 67 years old male patient. Complaints: Blurred vision and dizziness for 1.5 months. The patient has a medical history of hypertension, impaired glucose tolerance, and posterior circulation transient ischemic attack 1 month ago; the medicines used: aspirin $100 \mathrm{mg}$, clopidogrel $75 \mathrm{mg}$, atorvastatin $40 \mathrm{mg}$, verapamil hydrochloride $240 \mathrm{mg}+$ Trandolapril $4 \mathrm{mg}$. a,b,c) Image in CT-Angiography imaging consistent with $70 \%$ stenosis at the proximal of basilar artery (respectively coronal multiple intensity projection = MIP; sagital MIP; MIPreconstruction coronal planes) d,e) In the Angirogram, Lack of filling in the angiogram consistent with more than $70 \%$ stenosis at the proximal of basilar artery $\mathbf{f}, \mathbf{g}$ ) In the angirogram, decrease in the stenosis and improvement in the posterior circulation after angioplasty with "Gateway 2.75x15 mm balloon"
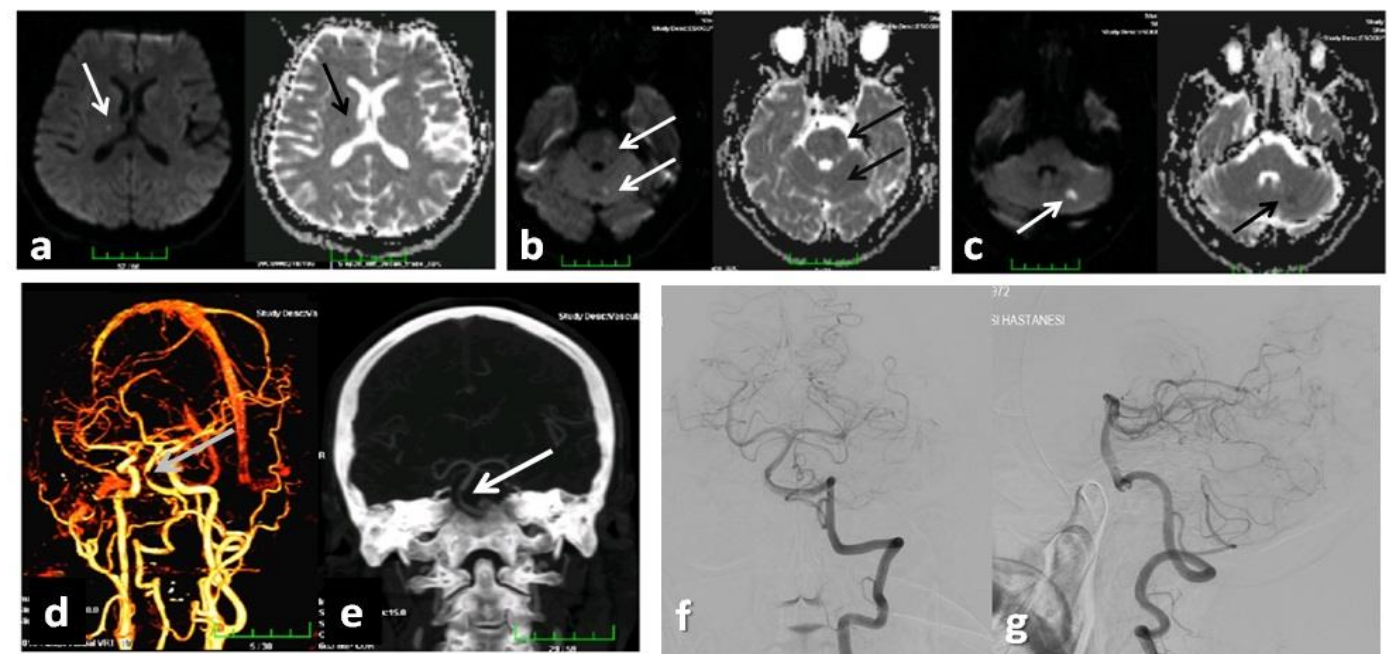

Figure IV. (Patient-4) 46 years old male patient. Complaints: Blurred vision and dizziness for 1.5 months (no features in the history). Neurological inspection is normal. Lesions consistent with acute infarct with hypointensity a) in the right thalamus, b) in the left hemipons and left anterior cerebellar lobe, c) in the left posterior cerebellar lobe; hyperintensity in DWI (diffusion-weighted imaging), and hypointensity in ADC (apparent diffusion coefficient) imagings. Decrease in contrast density in basilar artery in CT-angiography examinations obtained d) after the reconstruction performed with VRT (Volume Rendering Technique) e) with MIP (multiple intensity projection) technique. f) Conventional catheter angiography performed after 5 days the basilar artery angiogram was in normal limits in the anterior-posterior plane g) the angiogram in left lateral plane. (NOTE: Biomarkers for vasculitis were requested from the patient who was under aspirin + clopidogrel treatment and 3Tesla Vessel Wall magnetic resonance imaging was planned.)

Turkish Journal of Cerebrovascular Diseases 2019; 25 (1): 1-10 

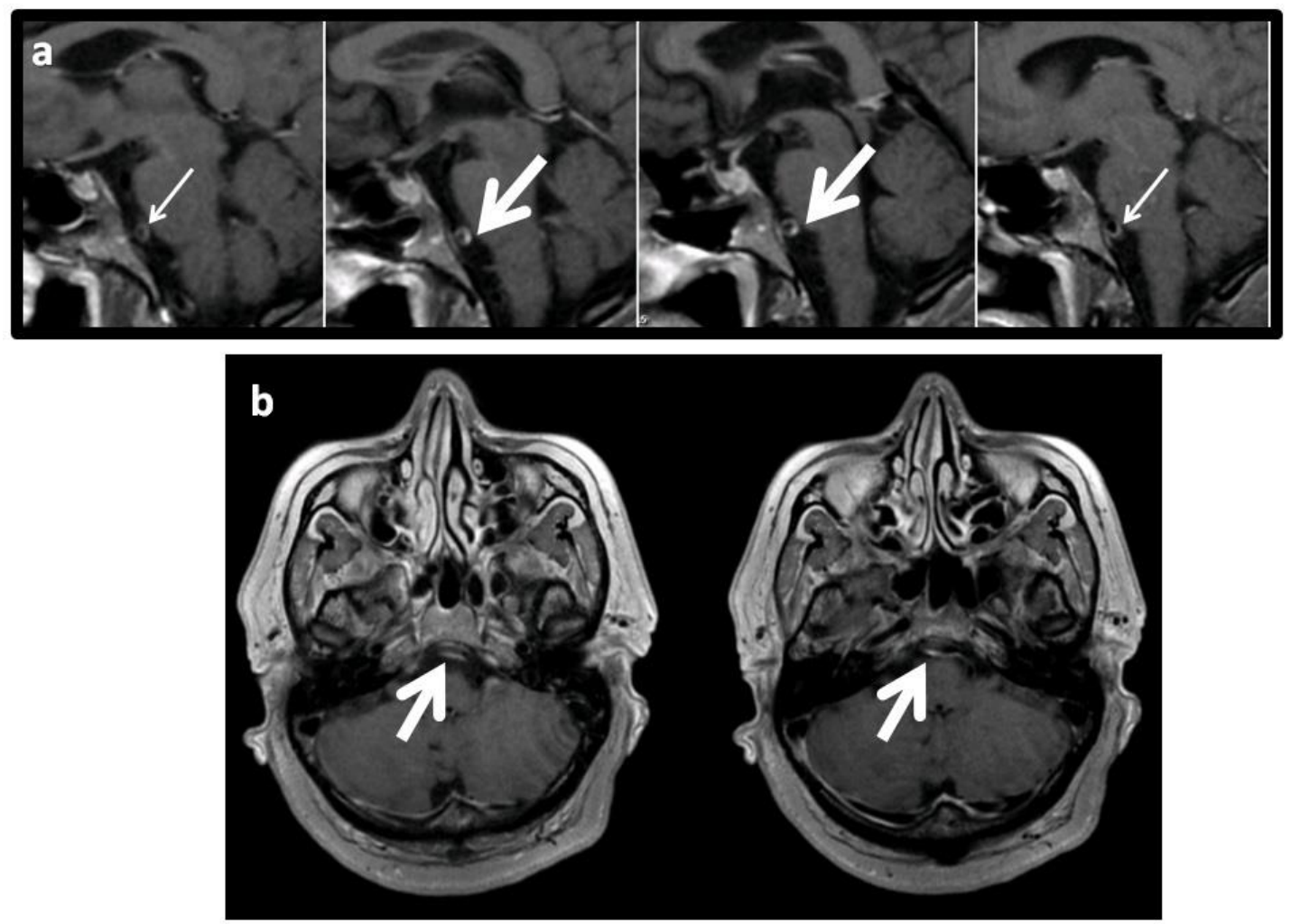

Figure V. (Patient-4 continued) For the same patient a) In sagittal plane, b) In axial plane; 3Tesla Vessel Wall magnetic resonance imaging revealed diffuse wall thickening in $1.5 \mathrm{~cm}$ segment in basilar artery wall, an $0.5 \mathrm{~cm}$ asymmetric thickening and contrasting on left lateral wall distal to this area (Evaluated in favor of inflammation in the artery wall).

\section{REFERENCES}

1. Bos D, Portegies M.L, van der Lugt A., Bos M.J, Koudstaal P.J, Hofman A, Ikram M. A. Intracranial carotid artery atherosclerosis and the risk of stroke in whites: the Rotterdam Study. JAMA neurology. 2014; 71(4): 405-411.

2. Yaghi S, Prabhakaran S, Khatri P, Liebeskind D.S. (2019). Intracranial Atherosclerotic Disease: Mechanisms and Therapeutic Implications. Stroke, STROKEAHA-118.

3. Mazighi M, Labreuche J, Gongora-Rivera F, Duyckaerts C, Hauw J.J, Amarenco P. Autopsy prevalence of intracranial atherosclerosis in patients with fatal stroke. Stroke, 2008; 39(4): 1142-1147.

4. Furie K.L, Kasner S.E, Adams R.J, Albers G.W, Bush R.L, Fagan S.C, Mitchell P.H. Guidelines for the prevention of stroke in patients with stroke or transient ischemic attack: a guideline for healthcare professionals from the American Heart Association/American Stroke Association. Stroke. 2011; 42(1): 227-276.

5. Bang 0. Y. Intracranial atherosclerosis: current understanding and perspectives. Journal of stroke 2014; 16(1): 27-35. doi:10.5853/jos.2014.16.1.27

6. Kim J.S, Nah H.W, Park S.M, Kim S.K, Cho K.H, Lee J, et al. Risk factors and stroke mechanisms in atherosclerotic stroke: intracranial compared with extracranial and anterior compared with posterior circulation disease. Stroke 2012;43:3313-3318.
7. As'ad Ehtsham, MD, MBBS, FAHA, Tanya N Turan, MD, MSCR. Intracranial large artery atherosclerosis Scott E Kasner, ed. UpToDate. https://www.uptodate.com (Last updated: Feb 06, 2019).

8. Banerjee C, Chimowitz M.I. Stroke caused by atherosclerosis of the major intracranial arteries.Circ Res. 2017; 120: 502-513.

doi: 10.1161/CIRCRESAHA.116.308441

9. Feldmann E, Wilterdink J.L, Kosinski A, Lynn M, Chimowitz MI, Sarafin J, et al.; Stroke Outcomes and Neuroimaging of Intracranial Atherosclerosis (SONIA) Trial Investigators. The Stroke Outcomes and Neuroimaging of Intracranial Atherosclerosis (SONIA) trial.Neurology. 2007; 68: 20992106. doi: 10.1212/01.wnl.0000261488.05906.c1

10. Walker M.D, Marler J.R, Goldstein M, Grady P.A, Toole J.F, Baker W.H, Young B. Endarterectomy for asymptomatic carotid artery stenosis. Jama. 1995; 273(18): 1421-1428.

11. Sanidas, E, Dangas G. Evolution of intravascular assessment of coronary anatomy and physiology: from ultrasound imaging to optical and flow assessment. European journal of clinical investigation. 2013; 43(9): 996-1008.

12. Majidi S, Sein J, Watanabe M, Hassan A.E, Van de Moortele P.F, Suri M.F.K, Qureshi A.I. Intracranial-derived atherosclerosis assessment: an in vitro comparison between virtual histology by intravascular ultrasonography, 7T MRI, and histopathologic findings. 
American Journal of Neuroradiology. 2013; 34(12): 22592264.

13. Bang O.Y, Toyoda K, Arenillas J.F, Liu L, Kim J.S. Intracranial large artery disease of non-atherosclerotic origin: recent progress and clinical implications. Journal of stroke. 2018; 20(2): 208.

14. Harteveld A.A, Denswil N.P, Siero J.C.W, Zwanenburg J. J.M, Vink A, Pouran B, Hendrikse J. Quantitative intracranial atherosclerotic plaque characterization at 7T MRI: an ex vivo study with histologic validation. American Journal of Neuroradiology. 2016; 37(5): 802-810.

15. Kim J.S, Bang O.Y. Medical treatment of intracranial atherosclerosis: an update. Journal of stroke. $2017 ; 19(3)$ : 261.

16. Chimowitz M.I, Lynn M.J, Howlett-Smith H, Stern B.J, Hertzberg V.S, Frankel M.R, Sila C.A. Comparison of warfarin and aspirin for symptomatic intracranial arterial stenosis. New England Journal of Medicine. 2005; 352(13): 1305-1316

17. Wang $Y$, Wang $Y$, Zhao X, Liu L, Wang D, Wang C, et al.; CHANCE Investigators. Clopidogrel with aspirin in acute minor stroke or transient ischemic attack. N Engl J Med. 2013; 369: 11-19.

18. Johnston S.C, Easton J.D, Farrant M, Barsan W, Battenhouse $\mathrm{H}$, Conwit R. Poisson S.N. Platelet-oriented inhibition in new TIA and minor ischemic stroke (POINT) trial: rationale and design. International Journal of Stroke. 2013; 8(6): 479-483.

19. Liu L, Wong KS, Leng X, Pu Y, Wang Y, Jing J, et al.; CHANCE Investigators. Dual antiplatelet therapy in stroke and ICAS: subgroup analysis of CHANCE. Neurology. 2015; 85: 11541162.

20. Wong K.S.L, Chen C, Fu J, Chang H.M, Suwanwela N.C, Huang Y.N, Zhao, Y. Clopidogrel plus aspirin versus aspirin alone for reducing embolisation in patients with acute symptomatic cerebral or carotid artery stenosis (CLAIR study): a randomised, open-label, blinded-endpoint trial. The Lancet Neurology. 2010; 9(5): 489-497.

21. Amarenco P, Albers G.W, Denison H, Easton J.D, Evans S.R, Held P, Minematsu K. Efficacy and safety of ticagrelor versus aspirin in acute stroke or transient ischaemic attack of atherosclerotic origin: a subgroup analysis of SOCRATES, a randomised, double-blind, controlled trial. The Lancet Neurology. 2017; 16(4): 301-310.

22. Kwon S. U, Cho Y.J, Koo J.S, Bae H.J, Lee Y.S, Hong K.S, Kim J.S. Cilostazol prevents the progression of the symptomatic intracranial arterial stenosis: the multicenter double-blind placebo-controlled trial of cilostazol in symptomatic intracranial arterial stenosis. Stroke. 2005; 36(4): 782-786.

23. Kwon S.U, Hong K.S, Kang D.W, Park J.M, Lee J.H, Cho Y J, Lee K.B. Efficacy and safety of combination antiplatelet therapies in patients with symptomatic intracranial atherosclerotic stenosis. Stroke. 2011; 42(10): 2883-2890.

24. Amarenco P, Benavente O, Goldstein L.B, Callahan III A, Sillesen H, Hennerici MG, Welch K.M.A. Results of the Stroke Prevention by Aggressive Reduction in Cholesterol Levels (SPARCL) trial by stroke subtypes. Stroke. 2009; 40(4): 1405-1409.

25. Chaturvedi S, Turan T.N, Lynn M.J, Kasner S.E, Romano J, Cotsonis G, Chimowitz M.I. Risk factor status and vascular events in patients with symptomatic intracranial stenosis. Neurology. 2007; 69(22): 2063-2068.

26. Turan T.N, Nizam A, Lynn M.J, Egan B.M, Le N.A, LopesVirella M.F, Janis L.S. Relationship between risk factor control and vascular events in the SAMMPRIS trial.
Neurology. 2017; 88(4): 379-385.

27. Uchiyama S, Demaerschalk BM, Goto S, Shinohara Y, Gotoh $\mathrm{F}$, Stone WM, et al. Stroke prevention by cilostazol in patients with atherothrombosis: meta-analysis of placebocontrolled randomized trials. J Stroke Cerebrovasc Dis. 2009; 18: 482-490.

28. EC/IC Bypass Study Group*. Failure of extracranialintracranial arterial bypass to reduce the risk of ischemic stroke: results of an international randomized trial. New England Journal of Medicine. 1985; 313(19): 1191-1200.

29. Bogousslavsky J, Barnett H.J.M, Fox A.J, Hachinski V.C, Taylor W. Atherosclerotic disease of the middle cerebral artery. Stroke. 1986; 17(6): 1112-1120.

30. Chimowitz M.I, Lynn M.J, Howlett-Smith H, Stern B.J, Hertzberg V.S, Frankel M.R, Sila C.A. Comparison of warfarin and aspirin for symptomatic intracranial arterial stenosis. New England Journal of Medicine. 20015; 352(13): 1305-1316.

31. Leung T.W, Kwon S.U, Wong K.S. Management of patients with symptomatic intracranial atherosclerosis. International Journal of Stroke. 2006; 1(1): 20-25.

32. Özdemir A.Ö, Kozak O.S. İntrakraniyal Aterosklerozda Nörogörüntüleme ve Endovasküler Tedavi. Turkiye Klinikleri Neurology-Special Topics. 2011; 4(3): 94-100.

33. Fiorella D, Woo H.H. Emerging endovascular therapies for symptomatic intracranial atherosclerotic disease. Stroke. 2007; 38(8): 2391-2396.

34. Chimowitz M.I, Lynn M.J, Derdeyn C.P, Turan T.N, Fiorella D, Lane B.F, Hoh B.L. Stenting versus aggressive medical therapy for intracranial arterial stenosis. New England Journal of Medicine. 2011; 365(11): 993-1003.

35. Derdeyn C.P, Chimowitz M.I, Lynn M.J, Fiorella D, Turan T.N, Janis L.S, Barnwell S.L. Aggressive medical treatment with or without stenting in high-risk patients with intracranial artery stenosis (SAMMPRIS): the final results of a randomised trial. The Lancet. 2014; 383(9914): 333341.

36. Kernan WN, Ovbagele B, Black HR, et al. Guidelines for the prevention of stroke in patients with stroke and transient ischemic attack: a guideline for healthcare professionals from the American Heart Association/American Stroke Association. Stroke. 2014; 45(7): 2160-2236.

37. Nguyen T.N, Zaidat O.O, Gupta R, Nogueira R.G, Tariq N, Kalia J.S, Qureshi A.I. Balloon angioplasty for intracranial atherosclerotic disease: periprocedural risks and shortterm outcomes in a multicenter study. Stroke. 2011; 42(1), 107-111.

38. Dumont T.M, Kan P, Snyder K.V, Hopkins L.N, Siddiqui A.H, Levy E.I. Revisiting angioplasty without stenting for symptomatic intracranial atherosclerotic stenosis after the stenting and aggressive medical management for preventing recurrent stroke in intracranial stenosis (SAMMPRIS) study. Neurosurgery. 2012; 71(6): 11031110.

39. SSYLVIA Study Investigators. Stenting of symptomatic atherosclerotic lesions in the vertebral or intracranial arteries (SSYLVIA) study results. Stroke. 2004; 35(6): 1388-1392.

40. Zaidat O.O, Fitzsimmons B.F, Woodward B.K, Wang Z, Killer-Oberpfalzer M, Wakhloo A, Pitzer P. Effect of a balloon-expandable intracranial stent vs medical therapy on risk of stroke in patients with symptomatic intracranial stenosis: the VISSIT randomized clinical trial. Jama. 2015; 313(12): 1240-1248. 